Ensino, Saúde e Ambiente -V10 (3), pp.1-15, Dez. 2017

\title{
CIÊNCIAS NA NARRATIVA DOS PROFESSORES: TRAJETÓRIAS DOCENTES E HERANÇA CULTURAL DA ESCOLA ${ }^{1}$
}

\section{SCIENCE IN TEACHERS' NARRATIVE: TEACHER'S TRAJECTORIES AND CULTURAL HERITAGE OF SCHOOL}

\author{
Barbara Gonçalves, Valença de Souza ${ }^{1}$, Giselle Rôças ${ }^{2}$, Maylta Brandão dos Anjos ${ }^{3}$ \\ ${ }^{1}$ Mestre pelo PROPEC/IFRJ, brainha83@hotmail.com \\ ${ }^{2}$ Docente do PROPEC/IFRJ, Campus Nilópolis, giselle.rocas@ifrj.edu.br \\ ${ }^{3}$ Docente do PROPEC/IFRJ, Campus Nilópolis, maylta.anjos@ifrj.edu.br
}

\begin{abstract}
RESUMO
A pesquisa busca conferir no Ensino de Ciências qualidade ao trabalho docente, permitindo um resgate metodológico acerca da ciência e de como ela está imbricada à memória cultural dos professores. Nesse campo, ciência e trajeto de vida são dimensões que precisam ser pensadas no seu aporte mais científico, o que não despreza as subjetividades perpassadas por este caminho. Para tanto, a pesquisa levanta a herança cultural por meio das narrativas de histórias de vida, colocando a escola em falas e memórias como referenciais para o ensino de ciências. Levanta elementos constituintes das memórias escolares no sentido da sua reconstrução para lapidação das práticas pedagógicas que redirecionam o sentido da propriedade acadêmica, ao revisitar os espaços anteriores que a constitui, atribuindo significados que auxiliam no processo da identidade dos sujeitos com a escola, ao se perceberem históricos, participativos e autônomos no seu processo de construção coletiva.
\end{abstract}

Palavras-chave: herança cultural; história de vida; memórias escolares.

\begin{abstract}
The scope of this research was to observe how cultural memories are linked with teacher's work, allowing a methodological background in order to do so. For this it was necessary the understanding of science and the life history of those subjects that were part of this study. We collect their life stories aiming the understanding of how science education teacher's and school were important for their process of becoming a new teacher. The school memories of the participants contribute with the construction of their identity as a teacher, and also contribute to their perception of the needs to build collectively the abilities in relation to autonomy.
\end{abstract}

Key-words: cultural heritage; life history; school memories

\footnotetext{
${ }^{1}$ Trabalho oriundo da dissertação da mestranda Bárbara Gonçalves Valença de Sousa desenvolvido no âmbito do Projeto Novos Talentos da CAPES
} 


\section{INTRODUÇÃO}

Entender a herança cultural de um grupo a partir da trajetória de vida de seus sujeitos auxilia na compreensão da situação atual em que o coletivo se encontra. E isso se faz necessário, pois o presente nos coloca novas questões que nos faz recorrer ao passado para buscar o sentido das ocorrências. Destarte, optamos pelo cunho qualitativo que trata de exterioridades ligadas à construção das subjetividades humanas e da ligação com aspectos mais concretos da vida. Assim, situa-se num campo firmado pela pesquisa qualitativa por via de um olhar mais específico e acurado que a investigação pode proporcionar. A possibilidade de resgatar e melhor compreender o processo dialético da realidade escolar na atualidade, converge com uma representativa característica do ensino de ciências, que é legitimado por e para esse processo.

A análise dos percursos narrativos nos permite uma pesquisa qualitativa que, para além de ver o outro como sujeito, o considera como "agência humana" imprescindível no ato de se fazer sentido nas contradições sociais (MATTOS, 2001). Por se constituir numa metodologia que revela as relações e interações ocorridas no interior da escola, de forma a abrir a "caixa preta" do processo de escolarização, a elegemos (MEHAN, 1992; RODRIGUES, ANDRADE e PEREIRA, 2013). A observação será participante, por ser a forma mais representativa possível do significado de uma pesquisa qualitativa, da sensibilidade e do refinamento do conhecimento sobre o contexto estudado. O pesquisador, neste caso, é também sujeito de sensibilidade histórica constituído dela e por ela. Portanto, a perspectiva dialética, nos servirá de base, pois esta consiste num ponto que qualifica a análise das falas e é capaz de desvendar ou descortinar a escola, lembrando que a todo instante há uma imbricação entre as histórias de vida e histórias docentes, já que o professor vive a sala de aula desde que era aluno.

Nesse sentido, a presente investigação abordou, por meio de entrevistas, a história da formação em ciências dos alunos normalistas ${ }^{2}$ participantes da pesquisa, realizando confluências com a formação em ciências oferecida em sua instituição de ensino para a aplicação no ensino normal, uma vez que considera-se importante diagnosticar como se dá a formação do educador que ensinará os aditamentos de um conhecimento científico crítico e contextualizado às necessidades dos alunos, a pesquisa

${ }^{2}$ Assumiremos a nomenclatura normalistas, pois temos alunos de ambos os sexos. 
buscou ouvir e compreender qual a situação da formação deste educador, num exercício proeminente para analisar por onde se norteará a sua prática.

Para realização da pesquisa foi necessário colocar às claras as intenções que estavam submersas num mosaico não explicativo dos sentidos socioeducativos. Ao analisar as falas, provocou-se o diálogo acadêmico permeado de sentido reflexivo acerca da realidade pensada e vivida. Assim, nos baseamos num "desempedrar" a via de cascalhos que postas nas marcas das falas, nos remete sempre ao significado da estrada, principalmente carregando-a do seu pleno sentido. No primeiro momento buscamos levantar o entendimento de herança histórica, cultural e qualidade do ensino. Desta feita, partiu-se para um estudo exploratório no cenário da pesquisa.

A pesquisa concorda com o pensamento de Carlos Rodrigues Brandão, que defende que os resultados de uma pesquisa são mais densos e significativos quando se constrói a metodologia desta, a partir de um questionamento inicial, que será norteador de como se dará as etapas do trabalho.

Podemos dizer que uma maneira mais fértil e mais gratificante de se compreender o significado do trabalho científico, em qualquer campo, é chegar ao seu estudo através de uma formulação pessoal e sempre ativa de problemas. Se eu sei as perguntas do que quero saber, embora não saiba ainda como buscar as respostas, fica mais fácil, mais proveitoso, aprender com os outros a como encontrar os meios e métodos de obter as respostas (BRANDÃO, 2009, p. 18).

Assim, a pergunta inicial foi: a herança cultural de um cenário escolar se constitui como uma das responsáveis pelo reconhecimento em educação desta instituição de ensino?

A partir desta indagação iniciamos nosso processo de execução da pesquisa, que tratou da análise documental e histórica e das falas da comunidade escolar, para a confirmação ou não do pressuposto inicial. Realizamos a investigação em três momentos. Nos quais nos dedicamos à revisão da bibliografia sobre a temática, avaliando as diferentes metodologias utilizadas em outros trabalhos com similaridade de objeto de pesquisa, com o intuito de reforçar o referencial teórico e prático desse estudo. O uso dos descritores "herança cultural escolar", "história de vida de professores" e "ensino de ciências" foram utilizados no banco de dados do Scielo e no Banco de Teses da Capes para identificar trabalhos que pudessem dialogar e embasar esse estudo. Após 
realizamos entrevistas semiestruturadas com alunos-professores, professores e funcionários da escola:

É este o propósito da entrevista: recuperar a trajetória do sujeito e, ao mesmo tempo, inserir e abrir um novo espaço ou um espaço para o novo na própria história de cada um. Como demonstramos interesse em saber o que os levou a serem professores, o que liam e escreviam, eles rememoram fatos passados, redescobrem a si próprios no relato de suas histórias e outro lado de sua trajetória se revela. Além disso, eles se surpreendem ao ouvirem a própria voz e percebem, através do seu relato, o quanto a história de cada um, por mais simples que seja, é plena de significado (KRAMER, 1997, p. 23)

Ocorreram encontros quinzenais com os sujeitos (normalistas do curso normal de uma escola pública) para discutir sobre a importância do resgate da memória e da participação deles na constituição da herança cultural de sua escola e como essas impressões e experiências estariam contribuindo para prepará-los para a atuação docente.

\section{A HISTÓRIA DESSE TRABALHO}

De uma forma geral, os alunos explanaram, na construção da identidade institucional, admiração e satisfação pelo percurso histórico da sua escola, mostraram satisfação por pertencerem a uma Instituição de ensino reconhecida e contemplada pela comunidade em seu entorno. O sentimento de pertença dos alunos pela escola, foi por percebido por todos os envolvidos na pesquisa, a cada momento dos encontros, nas falas e colocações.

Estes encontros fizeram parte do projeto Novos Talentos, um programa fomentado pela CAPES, que se apresentou na escola em subprojetos com temáticas e objetivos distintos, nos quais os alunos se inscreviam de acordo com seu interesse (SOUSA, 2012) do interesse e que culminou em uma feira de ciências. Nas atividades desenvolvidas para a pesquisa, os alunos foram levados a compreender como as memórias e experiências escolares contribuíram para o seu desenvolvimento intelectual e profissional, e como as suas vivências no seio da instituição tem contribuído para o reconhecimento em educação que essa, possui diante da comunidade em seu entorno (SOUSA e ANJOS, 2011). 
Nas atividades, solicitamos que os alunos respondessem a um questionário com seus dados e perguntas referentes ao que percebiam sobre a qualidade de educação de sua escola, gerando os seguintes resultados: 1- Idade: Três normalistas com 17 anos; 4 normalistas com 18 anos e 1 normalista com 19 anos. 2- Série: $4^{\circ}$ ano do ensino médio normal. 3: Sete normalistas afirmam que o ensino e a dedicação dos professores é excelente, cinco normalistas classificam o ensino de sua escola bom; enquanto outros quatro afirmaram que os professores são bons e estão sempre dispostos a ensinar.

Estes resultados nos permitiram concluir que os normalistas participantes da pesquisa reconhecem a qualidade de ensino e dos professores, destacando que são adequados e se empenham para que seus alunos aprendam significativamente, o conteúdo abordado. Não com um sentimento de detenção do saber, mas com o objetivo de contribuir para o exercício da criticidade daqueles que ensinam a partir da contextualização dos conteúdos que primam pela realidade dos alunos-professores, concordando com Bakhtin:

Na realidade, não são palavras o que pronunciamos ou escutamos, mas verdades ou mentiras, coisas boas ou más, importantes ou triviais, agradáveis ou desagradáveis, etc. A palavra está sempre carregada de um conteúdo ou de um sentido ideológico ou vivencial. É assim que compreendemos as palavras e somente reagimos àquelas que despertam em nós ressonâncias ideológicas ou concernentes à vida (BAKHTIN, 2004, p. 89).

Um ponto que deve ser destacado é o fato da escola possuir uma sala de memórias, onde está registrada grande parte das lembranças significativas. Encontramse neste local muitas fotos, convites de formatura, modelos de uniformes, fotos de todas as turmas, de todas as diretorias que assumiram o colégio, troféus de campeonatos ganhos por seus alunos-professores, troféus em reconhecimento a qualidade de ensino da instituição, dentre outros. Materiais que contam a história do cenário, e que fazem com que seus normalistas desejem perpetuar essa história durante o período em que estiverem estudando nele, criando o sentimento de pertencer a algo com referência, de herança cultural de bons resultados.

Para a atividade que questionava, como a escola contribuiu para a escolha pela profissão docente destes alunos-professores, tivemos considerações com muitos significados de satisfação pela escolha do curso. Quando o sujeito fala: "pois sabia que 
o passo que estava dando era pra vida inteira" (P1), mostra ter o discernimento de uma opção. Entretanto, a fala nos deixa crer que as opções não devem seguir um ritmo cartesiano, pois estando em construção e em fase de conhecimento, esses sujeitos, estão experimentando o mundo, para assim se definirem nele.

Outra fala que nos chama a atenção é quando o sujeito fala que no "segundo ano foi mais calmo, pois tinha passado aquela fase de experiência, ou seja, eu estava amadurecendo e encarando os trabalhos e palestras como algo natural” (P2). Este fato expressa a necessidade que a escola possui de integração para que o aluno-professores amadureça no seu processo de escolha profissional. Para tanto, autores como Freire, Freinet e Brandão nos auxiliam a entender a importância das atividades extra-classe, despertando os sentidos e amadurecendo os sentimentos em relação à escola e à formação que se dá em coletivo no mundo.

A fala "O terceiro ano foi ótimo para mim, já estava centrada naquilo que queria, contudo, as responsabilidades aumentavam mais e mais”, nos faz (P3) inferir a importância da processualidade na dimensão educacional. É esta que amadurece, fortalece os saberes e constrói, de forma lúcida, o futuro profissional.

Estes fatores são elucidados, sobretudo para o Ensino de Ciências, no momento em que o sujeito começa a perceber o mundo numa lógica que rompe com o analfabetismo científico e com o senso comum. Num pensamento que desmistifica, e faz ver a realidade por conclusões experimentais e experienciais.

O sujeito da pesquisa ao dizer que "Por fim, cheguei ao quarto ano, confesso que foi sofrido chegar até aqui, mas consegui" (P5), assinala que apesar do martírio, valeu a pena. Assim, vemos que a permanência e conclusão dos estudos está pautada em sacrifícios que virão laureados de ‘vitórias'.

O depoimento: "Este foi o mais gratificante, o que deixou muitas saudades, o que contarei aos meus futuros alunos"( $\mathrm{P} 2)$, destaca-se a alegria e o entusiasmo da primeira experiência docente, e demonstra o quanto esta prática é necessária para que o sentimento de professor aflore de fato. É perceptível a valorização dada à escola pelo incentivo que esta oferece ao desenvolvimento de conhecimentos e aprendizagens diversas: "aprendi uma nova dança, aumentando ainda mais minha cultura" (P5). Os normalistas têm a oportunidade de aprenderem música, danças, teatro, esportes, dentre outros. Assim a descoberta dessas novas potencialidades pelos normalistas em sua 
escola, faz com que o vínculo afetivo impere, determinando consequentemente, normalistas motivados e interessados pelos ensinamentos ali ministrados.

Outro ponto levantado na metodologia foi o questionamento: Como sua escola contribuiu para a sua formação docente? Nessa atividade os normalistas entrevistados recordaram as principais iniciativas de projetos escolares, evidenciando como as atividades fora da sala de aula também constituem práticas educacionais. A oportunidade de aprenderem um instrumento, uma dança, um esporte, de terem uma participação política nos assuntos da sua escola, dentre outros, foram altamente relevantes para a sua formação e não somente, as aulas teóricas da sala de aula, permitindo sua ampliação multicultural a partir da estimulação dos conhecimentos múltiplos.

Ao analisarmos as falas percebemos que a escola exerceu influência no memorial de formação "nesta instituição foi onde tive o maior incentivo para a minha formação docente, pois percebi o quanto é importante esta profissão (docente) para a sociedade" (P6). Certamente uma escola que valoriza a profissão docente diante de seus alunos-professores, deve valorizar de igual modo o trabalho do educador. Ao se sentir valorizado em seu próprio local de trabalho, o professor desempenha sua função com maior dedicação.

Ao analisarmos a frase citada por um dos sujeitos "Já no ginásio, tudo ocorreu bem, mas, nenhum professor me impressionou" (P6), percebemos o quanto "impressionar" é um agente importante na promoção da aprendizagem. Já que aulas interessantes, "impressionantes" e dinâmicas, oferecem uma atratividade que auxilia no interesse e na reflexão crítica dos alunos-professores, pois o educador tem o trabalho de planejar com criatividade o ensino de um componente curricular de maneira agradável e prazerosa de ser aprendido pelo aluno-professores.

O relato "Eu não era a mais inteligente da turma, mas ela me tratava muito bem. Tinha dificuldade na matéria, mas depois que conheci a professora, tudo mudou" (P5). Esse estudante reafirma o afeto como importante facilitador da aprendizagem, isto porque, o carinho e a empatia, por parte do professor, geram confiança, respeito e credibilidade no aluno-professores, que passa a ouvir com maior consideração, as palavras do seu educador. 
Valim (2000) aposta nas memórias dos docentes para a (re)construção de práticas pedagógicas, o que está em acordo com o proposto por Santos (2008) ao descrever que a evolução das pesquisas na área de didática, possibilitou a inclusão do estudo da "memória docente" em seus programas, a fim de resgatar o sentido e significado do trabalho e da profissão do professor que, segundo a autora,

Está rodeado de incertezas quanto ao seu futuro, por vários fatores, dentre eles: reguladores internos e externos dentro das instituições escolares, cansaço provocado por longas jornadas de trabalho, falta de tempo, recursos e estímulos à capacitação profissional, dentre outros, que tem levado muitos educadores ao desânimo e descrédito pela profissão (SANTOS, 2008, p. 76-77).

$\mathrm{Na}$ atividade Confluências com o ensino de ciências, solicitamos que os sujeitos preenchessem a um questionário semi-estruturado sobre suas memórias em relação ao ensino de ciências ministrado em sua instituição de ensino e como era a sua formação para ensinar ciências na educação básica. Todos os normalistas afirmaram que a escola dispõe de laboratórios, mas que estes nunca foram utilizados por eles, afirmaram possuir poucas aulas, explicitando: "Pelo fato do meu curso ser voltado para o magistério, não temos muita ênfase nas matérias científicas e exatas". Isso nos aponta uma lacuna grande na base da concepção de ciência na formação docente e mostra ainda como se segmenta disciplinarmente o ensino.

Quando questionamos se o ensino de ciências é facilitado com as aulas práticas, todos os normalistas afirmaram que sim, e que, as aulas práticas permitem a visualização dos conteúdos aprendidos teoricamente em sala de aula, entretanto, apesar de considerarem assim, ainda justificam uma ausência dessa prática na prática do curso.

Outra questão pesquisada foi a influência exercida pelo ensino de ciências compondo a memória dos alunos-professores, conforme observado em seus relatos "Lembro-me de quando plantamos pequenas mudas de plantas no jardim do colégio. Isso me motivou e me motiva até hoje a cuidar do meio ambiente"(P1), "Lembro-me de quando fiz em uma cartolina a célula vegetal e animal com miçangas e materiais diversos, além disso, participei de campanhas de reciclagem de lixo na escola” (P2), “Através da consciência de que a ciência é necessária para todos e aprofundando em conhecimentos, descobrimos formas de readaptação, melhorando a qualidade do nosso ambiente" (P3), "Minha escola a cada dia investe mais no aprendizado do ensino de 
ciências, principalmente nas séries do ensino fundamental e nos primeiros anos do curso normal. (P5), O Instituto focaliza bastante os assuntos de sustentabilidade, o qual, a cada dia vem aumentando o interesse"(P6), "Contribui para ficarmos cientes das doenças, sobre a preservação do meio ambiente, porque tivemos aulas que nos mostraram esses problemas e as soluções” (P7).

Esses exercícios permitiram refletir sobre as escolhas que fizeram na vida, e até que ponto estas, podem ter sido influenciadas por suas experiências educacionais nos primeiros anos da educação básica, e sobre comportamentos que não devem reproduzir, pois prejudicarão a aprendizagem dos seus futuros alunos.

Nesse sentido, Paulo Freire nos leva a refletir sobre a ideologia presente nos processos educativos, já que para ele, as palavras e atitudes do educador são carregadas de pensamentos ideológicos.

Saber igualmente fundamental à prática educativa do professor ou da professora é o que diz respeito à força, à vezes maior do que pensamos, da ideologia. É o que nos adverte de suas manhas, das armadilhas em que nos faz cair. É que a ideologia tem que ver diretamente com a ocultação da verdade dos fatos, com o uso da linguagem para penumbrar ou opacizar a realidade ao mesmo tempo em que nos torna "míopes" (FREIRE, 2000, p.14).

Assim, como educadores, devemos ter a preocupação com o amplo exercício da autonomia do pensamento e da prática educativa, que nos alimenta como cidadãos críticos, conscientes e participativos.

É oportuno destacar que as experiências mencionadas no decorrer deste trabalho e dos produtos educacionais oriundos do mesmo, pretendem ser de relevância para o autoconhecimento dos agentes envolvidos na pesquisa, pois quando estes refletem sobre suas memórias, se percebem em diferentes contextos e grupos sociais, que definem suas afinidades e subjetividades.

Além disso, os relatos obtidos com esta pesquisa nos permitem a percepção de que estão atrelados a outras vivências. As impressões documentadas pelos normalistas participantes da pesquisa nos aponta a importância constitutiva da memória e dos projetos que resgatam essa perspectiva nas escolas. Assim, a fala a seguir apresenta brevemente o que analisamos, "Quando a pesquisa começou, não pretendia somente adquirir novos conhecimentos, queria também me socializar com mais alunos e 
conseguir algum curso para o meu currículo" (P1), “O projeto ajudou nos meus propósitos. Comecei a fazer outras amizades durante o projeto e ganhei mais conhecimentos sobre assuntos que raramente eram abordados em sala de aula” (P2), "Aprendendo novos assuntos, comecei a ter mais interesse em um dia me formar professor, só para ensinar aos alunos do mesmo jeito que aprendi” (P3), "Durante o projeto, houve a fabricação de DVD's, livro, entre outros materiais, que foram interessantes... Esses materiais foram muito bem trabalhados e nós mesmos construímos" (P4), "Foram bastante adequados e elogiados, não só pelos alunos, mas, também, por outras pessoas” (P5), “As expectativas para o projeto eram boas, mas eu não sabia que seria tanto. Pensei que seria apenas mais um subprojeto" (P6), "Os subprojetos me ajudaram muito em termos de formação inicial para professora, sempre quis fazer uma faculdade de pedagogia. Não quero sair do ramo, apesar do professor não ser valorizado. Mas eu creio que esse quadro vai se reverter" (P8), "Através dos subprojetos, surgiu um interesse em mim pela formação superior (P9), "Quero fazer faculdade, pós-graduação, mestrado, doutorado e assim por diante. Quem é professor, nunca para de estudar, sempre tem novidades e trabalhos" (P10), "As minhas expectativas foram superadas, pensava que seria uma coisa chata. Só escrever e ler... mas não foi assim, fizemos dinâmicas de modo criativo, fizemos DVD, um livro... Uma experiência muito boa que fica como herança cultural para nós e para a escola"(P11).

Esses relatos assinalam a oportunidade de os sujeitos em repensarem a prática e expressarem suas ideias acerca da profissão que desejam exercer. Assim, percebemos que os normalistas se sentiram ouvidos na sua construção da história e na de sua escola. Sentiram-se empoderados no relato das suas histórias de vida e na confecção de um livro, pensado exclusivamente para eles; em terem suas histórias, que estão entrelaçadas com a história da sua escola, relatadas em um documentário e em produzirem e editarem um vídeo com situações do cotidiano escolar, exercendo autoria de ideias nesse exercício ${ }^{3}$.

Percebemos também que a forma como os normalistas observavam a vida foi alterada após a experiência que vivenciaram com este projeto, pois foram levados a um amadurecimento maior, a partir do estímulo à criticidade, à argumentação, ao trabalho em equipe, à construção de ideias coletivas e individuais para a resolução de problemas,

\footnotetext{
${ }^{3}$ http://www.propec-ifrj.com.br/sites/default/files/teses/livro_historia_de_vida_dos_alunos_professores.pdf
} 
enfim, começaram a perceber que podiam contribuir de maneira essencial para a conclusão dos objetivos do projeto e para a construção dos produtos oriundos do projeto como um livro que conta as suas histórias de vida, levantando a sua memória cultural e seu capital social. Recuperaram o protagonismo do seu saber pelo valor e reconhecimento de quem são e de sua história de vida. Nesse sentido concordamos com o exposto por Silva Junior (2015) ao criticar o modelo de formação de professores, alegando que ao não prepará-lo para as novas e diversas, por vezes ambíguas, situações acaba gerando uma variedade de concepções alternativas sobre a própria profissão e o seu papel. Assim comumente vemos o professor ser considerado como "Professor Pesquisador", "Professor Reflexivo", "Professor Intelectual", "Professor Transformador", "Professor Autônomo", entre outros.

É importante destacar que alguns normalistas mencionaram que o projeto foi tão relevante em suas vidas que ficará para sempre em sua memória. Essa fala demonstra que os trabalhos desenvolvidos no projeto foram significativos e serão lembrados por isso, a fim de auxiliá-los em sua jornada pela profissão docente.

É nesse campo semântico que se expressa uma história e se torna concreta dentro do papel social, e é nessa história que novos contornos vão acontecendo, ora ligados aos aspectos de sua matriz formadora, ora despregando-se dela. A perspectiva aqui foi a de contextualizar que escola é essa formada na contemporaneidade por desafios.

Por ser vivo o conhecimento que se apreende, há sempre uma história formadora que merece ser revisitada nos mais diferentes contextos e recortes. Buscar no passado outras ligações que ajudem a entender o reconhecimento em educação de uma escola dentre tantas que se tem é buscar desvendar o que está por traz dos resultados. Passar pela história cultural local, formadora de opiniões e resultados que criam uma base de análise própria.

O conceito de herança histórica parece ter ficado diluído na constituição dos afazeres cotidianos, se perderam na rapidez da vida e no imediatismo das realizações. Por isso, dar esta parada e pensar na compreensão herdada é pensar no processo de que somos historicamente herdeiros, seja ele referente à história da escola proposta, seja ele referente aos resultados que podem ser expressos por uma herança histórica.

Pensar dimensões que habitam a escola é também refletir uma nova experiência que rearranja a juventude no que ela se apresenta hoje. Refletir essa questão não para 
metabolizar o que já foi, mas para ver diferente do que se vê, buscando as dobras e as reentrâncias dos fatos, dos acontecimentos que possam explicar um campo de ações e de resultados.

Ao se recuperar a história de uma instituição social formadora de grandes coletivos, como a escola, torna-se dinâmico o presente na perspectiva do rompimento com as determinações postas, tornando-a viva e passível de grandes mudanças. Trata-se, então de um devir histórico a ser construído na sua materialidade e na ética das relações que se estabelecem entre os sujeitos dessa própria escola.

\section{CONSIDERAÇÕES FINAIS}

A pesquisa qualitativa, baseada na trajetória dos sujeitos buscou levantar a herança cultural, por meio das atividades realizadas e por via das narrativas de histórias de vida, buscou compreender como o cenário da escola trabalhada tem se constituído em memórias e falas, através da herança histórica. Para tanto, utilizou como recorte os referenciais para o ensino de ciências. Buscou, ainda, o sentido da qualidade acadêmica e do processo da identidade com a escola, ao levar os sujeitos constitutivos destas a se perceberem históricos, participativos e autônomos no seu processo de construção coletiva.

As conclusões apresentadas pelos normalistas nos permitiram compreender a importância da escola, para o grupo focal em questão. Esse trazia palavras carregadas de sentimentos e emoções, carregadas de um conteúdo, o vivencial. Foi possível perceber o quanto a escola contribuiu e contribui para a formação e é constitutiva da memória dos sujeitos que por ela passa e tem nela os primeiros passos de ação profissional, não somente intelectual e cultural, mas para outras habilidades e emoções, auxiliando em diversos aspectos formadores. Percebemos também, o quanto os normalistas se sentem altivos por serem parte integrante da herança cultural e histórica de uma instituição de ensino conceituada e admirada pela sociedade. Assim, foi o percurso dessa pesquisa, a qual buscou fortalecer os laços afetivos dos normalistas com a sua escola de formação, com as suas escolhas, e destas com seus alunos.

Com base na análise das falas, na recuperação de algumas histórias, percebemos que o novo está sedimentado numa herança pregressa, seja para transgredi-la, seja para revivê-la em outro formato. E assim, entender o desempenho atual desta escola tendo 
como suporte suas historiografias, fortalece o elo existente entre passado e presente, além de permitir uma maior legitimação do ensino de ciências no discurso interdisciplinar. Não há como se pensar o presente sem trazer a tona o passado, a história formadora do que se há e do que se pretende e esse exercício permite uma maior apropriação do discurso emitido pelo ensino de ciências quando a apropriação da história e de suas consequências é entendida pelo mesmo.

Integrar o olhar no sentido de criar as condições de uma análise que observe nas sutilezas, leituras e pistas da realidade, é fazer pesquisa na sua mais fina objetividade e torná-la acessível, inteligível e lógica, caracterizando a essência do ensino de ciências. É o que nos alvitramos fazer na propositiva desta análise. Isto porque entendemos que a educação, como processo de conquista e construção social, é ação de análise contínua. Nessa base as transformações acontecem no sentido da qualidade educacional, no suporte a esta e na consecução de medidas que tornem a escola cada vez mais democrática, justa, inclusiva, viável para a constituição dos aspectos técnicos, tecnológicos e científicos.

\section{AGRADECIMENTOS}

Gostaríamos de agradecer a todos os normalistas envolvidos nesse estudo, a Direção da escola e demais professores que possibilitaram o acesso e a coleta dos dados, ao IFRJ, à CAPES (Edital do Novos Talentos) e a FAPERJ que financiaram essa pesquisa.

\section{REFERÊNCIAS}

BAKHTIN, M. M. Marxismo e filosofia de linguagem. São Paulo: Hucitec, 2004.

BARTNIK. H. D. S. As relações de poder e a organização do trabalho pedagógico.

Ciência e opinião, Curitiba, v.1, n. 2, 2003. Disponível em: htpp:// www.cienciaeopiniao.unicenp.edu.br. Acesso em: 28/05/2015

BOURDIEU, P. O poder simbólico. Rio de Janeiro: Bertrand Brasil, 1989.

A economia das trocas simbólicas. São Paulo: Perspectiva, 1992.

2009. 
BRANDÃO, C. R. Teorias, métodos e técnicas da pesquisa de campo, São Paulo: Brasiliense

BRASIL. Secretaria de Educação Fundamental. Parâmetros curriculares nacionais: Ciências Naturais. Brasília: MEC /SEF, p. 138, 1998.

FAZENDA, I (Org). Metodologia da Pesquisa Educacional. São Paulo: Cortez, 2002.

FOUREZ, G. Crise no ensino de ciências? Investigações em Ensino de Ciências, v. 8, n. $2, \quad$ p. 109-123, 2003.2 Disponível em: http://www.if.ufrgs.br/ienci/artigos/Artigo_ID99/v8 n2 a2003.pdf. Acesso em: 03/05/2015.

FREIRE, P. Pedagogia da autonomia. Saberes necessários à prática educativa. $21^{\text {a }}$ edição. São Paulo: Paz e Terra, 2002.

GEERTZ, C. A interpretação das culturas. Rio de Janeiro: LTC, 2014.

MORAES, N. A. Discurso, análise do discurso e memória. S/D. Disponível em: http://www.nilsonmoraes.pro.br/nm/NM-pdf.pdf. Acesso em: 20/05/11.

OLIVEIRA, S. M. M. Memórias de professores de ciências e biologia no início de Carreira docente: conflitos e tensões. Dissertação de Mestrado. Belém: NPADC/UFPA, 2004.

PEREIRA, D. R. M.; SILVA, T. P.; RUBINI, A. I. R. A representação do professor no memorial de formação: categorias emergentes no discurso dos alunos do $3^{\circ}$ ano do curso de letras, $2006 . \quad$ Disponível em: http://www.filologia.org.br/xiicnlf/textos completos/ Acesso em 10/10/2014.

SILVA JUNIOR, A. F. Estágio supervisionado na formação de professores de história: relação teoria e prática. Interfaces da Educação, Paranaíba, v.6, n.16, p.103-117, 2015. http://periodicos.uems.br/novo/index.php/interfaces/article/view/4489/2882 Acesso em $15 / 06 / 2015$

SOUSA, B. G. V.; ANJOS, M. B. História de vida dos alunos professores. Rio de Janeiro, Publit, 2011. Disponível em: $\underline{\text { http://www.propec- }}$ ifrj.com.br/sites/default/files/teses/livro historia de vida dos alunos professores.pdf Acesso em 10/10/2014. 
SOUSA, B. G. V. Herança cultural e histórias de vida: a escola em falas e memórias - formação de professores no ensino de ciências. Dissertação de Mestrado, Programa de Pós-Graduação Stricto Sensu, Mestrado Profissional em Ensino de Ciências, Nilópolis, RJ, 2012. Disponível em: http://www.propecifrj.com.br/sites/default/files/teses/dissertacao_barbara_goncalves_valenca_de_sousa.pd f Acesso em 10/10/2014.

_142_o_mestrado_profissional_em_ensino.pdf. Acessado em maio de 2010. 